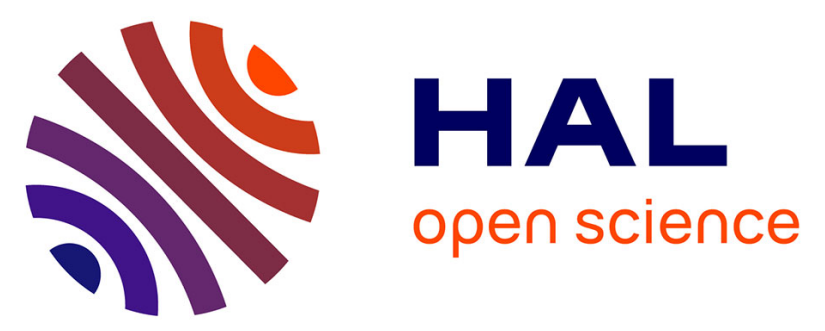

\title{
Atomic scale insight into the formation, size and location of platinum nanoparticles supported on $\gamma$-alumina
} Ana Teresa Fialho Batista, Walid Baaziz, Anne-Lise Taleb, Johan Chaniot, Maxime Moreaud, Christèle Legens, Antonio Aguilar-Tapia, Olivier Proux, Jean-Louis F Hazemann, Fabrice Diehl, et al.

\section{To cite this version:}

Ana Teresa Fialho Batista, Walid Baaziz, Anne-Lise Taleb, Johan Chaniot, Maxime Moreaud, et al.. Atomic scale insight into the formation, size and location of platinum nanoparticles supported on $\gamma$-alumina. ACS Catalysis, 2020, 10 (7), pp.4193-4204. 10.1021/acscatal.0c00042 . hal-02871593

\section{HAL Id: hal-02871593 \\ https: / hal-ifp.archives-ouvertes.fr/hal-02871593}

Submitted on 17 Jun 2020

HAL is a multi-disciplinary open access archive for the deposit and dissemination of scientific research documents, whether they are published or not. The documents may come from teaching and research institutions in France or abroad, or from public or private research centers.
L'archive ouverte pluridisciplinaire HAL, est destinée au dépôt et à la diffusion de documents scientifiques de niveau recherche, publiés ou non, émanant des établissements d'enseignement et de recherche français ou étrangers, des laboratoires publics ou privés. 


\title{
Atomic scale insight into the formation, size and location of plati- num nanoparticles supported on $\gamma$-alumina
}

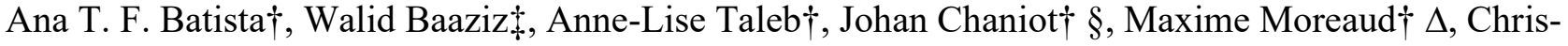 \\ tèle Legens $\dagger$, Antonio Aguilar-Tapia ${ }^{\varphi}$, Olivier Proux ${ }^{\phi}$, Jean-Louis Hazemann ${ }^{\varphi}$, Fabrice Diehl $\uparrow$, Céline \\ Chizallet $\dagger$, Anne-Sophie Gay†, Ovidiu Ersent** and Pascal Raybaud †*
}

$†$ IFP Energies nouvelles, Rond-point de l'échangeur de Solaize, BP 3-69360 Solaize, France

†Institut de Physique et Chimie des Matériaux de Strasbourg, CNRS-Université de Strasbourg, 67034 Strasbourg, France

§Laboratoire Hubert Curien, CNRS-Université Jean Monnet de Saint-Etienne, 42000 Saint Etienne, France

$\triangle$ Centre for Mathematical Morphology, MINES ParisTech, 77305 Fontainebleau, France

๑ Institut Néel, UPR 2940 CNRS-Université Grenoble Alpes, F-38000 Grenoble, France

ф OSUG, UMS 832 CNRS-Université Grenoble Alpes, F-38041 Grenoble, France

Keywords: Platinum, nanoparticles, alumina, electron microscopy, electron tomography, DFT, EXAFS

\begin{abstract}
The clear description of the morphology and location, with respect to the support, of metallic sub-nanometric particles remains a current experimental strenuous challenge in numerous catalytic applications. High resolution-HAADF-STEM coupled with in situ and tomographic analyses are undertaken on platinum $(\mathrm{Pt})$ active phase supported on chlorinated alumina $(\gamma-$ $\mathrm{Al}_{2} \mathrm{O}_{3}$ ) with 0.3 and $1 \% \%_{\mathrm{w} / \mathrm{w}} \mathrm{Pt}$ loadings highlighting the formation of flat nanoparticles (NPs) of $0.9 \mathrm{~nm}$ diameter and Pt single atoms (SAs) in the reduced state. While SAs and weakly cohesive clusters are predominantly observed in the oxide state, with a coordination sphere of $\mathrm{Pt}$ composed of $\mathrm{O}$ and $\mathrm{Cl}$ as revealed by EXAFS, the ratio between SAs and Pt NPs in the reduced state is found to be about 2.8. This ratio is not affected by metal loading which increases both the total number of NPs and SA. Electron tomography reveals that the vast majority of NPs are located on the edges or defects (steps, kinks) of the $\gamma$-alumina support crystallites. Density functional theory calculations further highlight the optimized structures of NPs located at the $\gamma-\mathrm{Al}_{2} \mathrm{O}_{3}(110)-(100)$ edge and nearedge with a stability competing with NPs located either on the (110) or on the (100) $\gamma-\mathrm{Al}_{2} \mathrm{O}_{3}$ facet. A mathematical analysis of the segmented volumes shows that the average geodesic distances between NPs is linked to Pt loading: $9 \mathrm{~nm}$ for $1 \%_{\mathrm{w} / \mathrm{w}} \mathrm{Pt}$, and $16 \mathrm{~nm}$ for $0.3 \% \%_{\mathrm{w} / \mathrm{w}} \mathrm{Pt}$. Evaluation of support tortuosity descriptors using the nanoparticles positions confirms a uniform distribution on the support. A square network geometric model compatible with the geodesic distances between NPs reveals that 1 to 5 NPs can be present at the same time on each alumina crystallite depending on Pt loading.
\end{abstract}

\section{INTRODUCTION}

Noble-metal particles dispersed on oxide supports have several industrial applications from fine chemistry to petroleum refining (naphtha reforming), pollution abatement and biomass conversion. ${ }^{1,2}$ This is the case for platinum supported on $\gamma$ $\mathrm{Al}_{2} \mathrm{O}_{3}$, which has been consistently studied in the literature with the progress of characterization techniques, mostly using model systems. ${ }^{3-10}$

For many structure sensitive reactions, ${ }^{11}$ the reactivity of metal active sites provided by $\mathrm{Pt}$ particles depends on their size and shape. Catalyst improvement thus depends on advancing knowledge of these features. Overall, for platinum loadings inferior to $1 \% \%_{\mathrm{w} / \mathrm{w}} \mathrm{Pt}$, particles have a size of about $1 \mathrm{~nm}$ and are highly dispersed on the alumina support. ${ }^{12-17}$ These nanoparticles (NPs) are formed during reduction, ${ }^{13,18}$ as the catalysts in oxide state display mostly isolated Pt atoms. ${ }^{12}$ The NPs of nanometric or even sub-nanometric sizes were described as having a bi-planar raft-like morphology. ${ }^{12,13,19}$ In addition, single atoms (SAs), binuclear and trinuclear Pt species were also observed in reduced catalysts. ${ }^{8,12,13}$
NP size and shape are inherently associated to its chemical interaction with the support, ${ }^{20}$ depending on the particle's location on the alumina nano-crystallite facets. Indeed, density functional theory (DFT) calculations suggested that the flat bi-

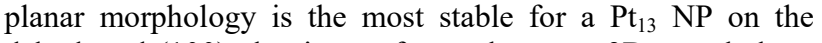
dehydrated (100) alumina surface, whereas a 3D morphology is favored on hydrated (110) surface. ${ }^{21}$ This modification of the NP shape as a function of the environment was recently assigned to a "ductility effect", 22 which implies the dynamic reconstruction of the Pt based $\mathrm{NP}^{23-27}$ as a function of support surface, ${ }^{21}$ reaction conditions ${ }^{7,28}$ or chemical composition of $\mathrm{NP}^{12,22}$ (when a second metallic element is added for instance).

Depending on the targeted applications, it is sometimes required to promote the acidity of the alumina support by chlorine doping. That is the case for isomerization or reforming processes. $^{29,30}$ In these cases, the catalyst belongs to the wellknown class of metal/acid bifunctional catalyst, for which the distance between metallic/acid sites is a known driver for selectivity variations ${ }^{31}$ interpreted in light of the "intimacy criterion" described originally by Weisz. ${ }^{32}$ When both metallic and acid sites are deposited on the same support, as in naphtha 
reforming catalysts, the fine control of the distance between them requires their location to be clearly ascertained. A preferred anchoring site on the alumina surface for Pt NPs has yet to be unequivocally found, especially for industry relevant samples. A ${ }^{27}$ Al MAS NMR study realized by Kwak et al. ${ }^{5}$ concluded that supported platinum oxide, assumed to be $\mathrm{PtO}$, is bonded to $\mathrm{Al}_{\mathrm{V}}$ surface sites. These are considered to be mostly present on the alumina (100) surface after dehydration by thermal treatment at high temperatures. The morphology of a low surface area alumina with large $20 \times 70 \mathrm{~nm}$ crystallites exposing (110) and (111) type surfaces was analyzed in detail by electron microscopy. ${ }^{33}$ A sample containing $5 \%_{\mathrm{w} / \mathrm{w}}$ Pt was found to exhibit large NPs equally present on both surface terminations. In both cases, these results can hardly be extrapolated to commercial catalysts in which significantly lower metal loadings (generally one order of magnitude smaller) ${ }^{34}$ are used, leading to highly dispersed NPs supported on high surface area alumina with smaller crystallites $(<20 \mathrm{~nm})$.

Additionally, platinum as metal active site has been used in several studies looking to explore the potential of single atoms supported on alumina ${ }^{3,5,18,35-37}$ or other supports such as nitrogen-doped microporous hierarchical carbon ${ }^{38}$ as well as ceria $^{39-42}$. Two challenges are common to all preparations, concerning the formation of nanoparticles upon activation and the fact that the SAs may not be intrinsically more active than NPs. SA sintering was found to be particularly favorable upon reduction in the case of $\mathrm{Pt}_{1} / \mathrm{Al}_{2} \mathrm{O}_{3},{ }^{18,35}$ although single atom dispersion was maintained after reduction at $200^{\circ} \mathrm{C}$ under $5 \% \mathrm{H}_{2}$ and after hydrosilylation reaction test at $100^{\circ} \mathrm{C}$ when nano-rod alumina was used. ${ }^{3}$ These are relatively mild activation and reaction conditions, but the remarkable SA stability is clearly associated with the alumina crystallites morphology.

In the present work, metallic Pt phase supported on a chlorinated alumina $\left(\gamma-\mathrm{Al}_{2} \mathrm{O}_{3}\right)$ is comprehensively studied using advanced electron microscopy techniques with the goal of a) elucidating the NP formation during reduction, b) evaluating the size and morphology of NPs on the reduced catalyst, c) describing NP location on the alumina crystallites and of d) quantifying the distance between NPs.

Transmission electron microscopy (TEM) is a cutting-edge technique for characterizing the morphology of supported NPs. In particular, high-angle annular dark-field - scanning transmission electron microscopy (HAADF-STEM) mode is widely used for morphological characterization at the nanoscale of supported noble metal particles and is the best tool for the objectives at hand. HAADF detection mode is based on the Rutherford scattering process, so image intensity is roughly proportional to the square of the atomic number of the material. $^{8}$ This means high $\mathrm{Z}$ elements such as metals appear with high contrast as opposed to the oxide support. Aberrationcorrected instruments have allowed for high-resolutions in the range of $0.1 \mathrm{~nm}$ with a good signal to noise ratio. ${ }^{8,13}$ With the recent technological advancements in electron microscopy, other techniques were coupled to the HAADF imaging mode in particular: a) electron tomography, which provides spatial information through $3 \mathrm{D}$ reconstruction of an object ${ }^{43-46}$ and $b$ ) in situ/environmental TEM, with which the dynamic evolution of metal particles can be observed in real time during thermal treatments. $^{47-50}$
Herein, we combine HR-HAADF-STEM with environmental TEM and electron tomographic experiments to get unequaled level of information regarding the Pt NPs formation, size, morphology and most importantly, their location on the alumina support and their inter-particular distance. In addition, EXAFS analysis at $\mathrm{Pt} \mathrm{L}_{3}$ edge provides complementary insights into the local distance of the Pt atoms with neighboring atoms. For this, two industrial type catalysts were prepared with $0.3 \%$ and $1 \%_{\mathrm{w} / \mathrm{w}}$ Pt loading supported on a high surface $\gamma$ alumina doped with $1.3 \%_{\mathrm{w} / \mathrm{w}}$ chlorine. Tomographic segmented models are obtained and quantified geodesic distances evaluated thanks to mathematical analysis. DFT calculations quantify the stability and provide an atomistic view of the local environment of the platinum particles at the specific locations identified experimentally.

\section{EXPERIMENTAL SECTION AND METHODS}

Catalyst preparation. Catalysts were prepared by diffusional impregnation of $\gamma-\mathrm{Al}_{2} \mathrm{O}_{3}$ extrudates prepared from TH100 commercial boehmite powder from Sasol $\left(\mathrm{S}_{\mathrm{BET}}=149 \mathrm{~m}^{2} / \mathrm{g}\right.$ by $\mathrm{N}_{2}$ physisorption) with a $\mathrm{H}_{2} \mathrm{PtCl}_{6}$ and $\mathrm{HCl}$ solution, followed by drying overnight and finally calcination at $520^{\circ} \mathrm{C}$ for $2 \mathrm{~h}$ under dry air (heating $5^{\circ} \mathrm{Cmin}^{-1}, 1 \mathrm{Lmin}^{-1} \mathrm{~g}_{\text {cat }}{ }^{-1}$ ). The chlorine loading was increased by thermal treatment at $520^{\circ} \mathrm{C}$ by adding dichloropropane $\left(\mathrm{C}_{3} \mathrm{H}_{6} \mathrm{Cl}_{2}\right)$ to the air flow in the proportion of $1 \%$ wt per gram of catalyst. The catalyst obtained after this treatment is referred to as being "oxide". The oxide catalysts were reduced ex situ under $\mathrm{H}_{2}$ flow at $500^{\circ} \mathrm{C}$ for $2 \mathrm{~h}$, after a 30 min pre-calcination at $520^{\circ} \mathrm{C}$ under dry air (heating $5^{\circ} \mathrm{Cmin}^{-1}$, $\left.1 \mathrm{Lmin}^{-1} \mathrm{~g}_{\text {cat }}{ }^{-1}\right)$ to remove residual chemisorbed water. Two catalysts were prepared so as to have a chlorine loading of $1.3 \%_{\mathrm{w} / \mathrm{w}}$ and platinum loading of $0.3 \%_{\mathrm{w} / \mathrm{w}}$ or $1 \% \%_{\mathrm{w} / \mathrm{w}}$ (measured for oxide samples by $\mathrm{X}$-ray fluorescence). They are referred to as oxide or reduced $0.3 \% \mathrm{Pt} / \gamma-\mathrm{Al}_{2} \mathrm{O}_{3}-\mathrm{Cl}$ and $1 \% \mathrm{Pt} / \gamma-\mathrm{Al}_{2} \mathrm{O}_{3}-\mathrm{Cl}$, respectively. Since the chlorine surface concentration may impact the stability of Pt NP,,$^{29,51-53}$ the chlorine loading was kept fixed at $1.3 \%_{\mathrm{w} / \mathrm{w}}$, a value close to the experimental ones used for naphtha reforming catalysts, in particular for the two samples throughout the present study.

Scanning transmission electron microscopy. High resolution high angle annular dark field in scanning transmission electron microscopy (HR-HAADF-STEM) imaging, HAADF-STEM in situ reduction experiments and HAADF-STEM electron tomography analyses were carried out on a Cs-corrected JEOL JEM $2100 \mathrm{~F}$ microscope, operated at $200 \mathrm{kV}$, equipped with a JEOL HAADF detector. For the HR-STEM images, the camera length used in the HAADF mode was $10 \mathrm{~cm}$, corresponding to inner and outer diameters of the annular detector of 60 and $160 \mathrm{mrad}$, respectively. The size of the electron probe in STEM mode is $0.11 \mathrm{~nm}$. Before the STEM analyses, the powdered samples were deposited without solvent on a 300 mesh holey carbon copper grid. The nanoparticle size histograms and average size were obtained from at least 200 measurements from images taken at the same magnification. Nanoparticle morphology and shape was studied measuring HAADF intensity to estimate the number of $\mathrm{Pt}$ atoms stacked perpendicularly to the electron beam (n) from the intensity of atomic column (I), given that the image intensity is roughly proportional to the square of the mean atomic number $(\mathrm{Z})$ of the analyzed area. ${ }^{8}$ As the measurements were performed on thin areas, alumina contribution to intensity was neglected in a first 
approximation. The intensity of several single atoms were measured, to estimate the proportionality factor between $\mathrm{I}_{\mathrm{SA}}$ and $\mathrm{Z}_{\mathrm{SA}}{ }^{2}$. Starting from the assumption that the atomic number of a column composed of $\mathrm{n} \mathrm{Pt}$ atoms is equal to $\mathrm{nZ}_{\mathrm{SA}}$, by

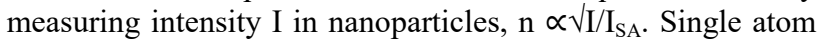
population was quantified through a number of SA to number of NP ratio calculated for several images at the same magnification.

Electron tomography. The powdered samples were deposited without solvent on a previously plasma cleaned 200 mesh holey carbon grid which was mounted on a tomographic single-tilt sample holder. For the two reduced catalysts the tilt series were acquired in HAADF STEM mode with $2.5^{\circ}$ increments by using the tomography plug-in of the Digital Micrograph software, which controls the specimen tilt step by step, the defocusing and the specimen drift. Two series per sample of circa $200 \mathrm{~nm}$ large objects composed of less than 20 alumina crystallites were acquired. Image alignment was performed through fiducial-less methods, namely a combination of crosscorrelation and center of mass methods using the IMOD software. $^{54}$ The reconstructed $3 \mathrm{D}$ volumes were obtained using the algebraic reconstruction technique $(A R T)^{55}$ implemented in the TomoJ plugin ${ }^{56}$ in the ImageJ software. Segmented 3D models were constructed using the displaying capabilities and the isosurface rendering method on the Slicer software. ${ }^{57,58}$

Geometrical analysis of the segmented volume. Inter-NP distance calculations and tortuosity assessments were conducted on the segmented volumes using the M-tortuosity algorithm $^{59,60}$ that combines geometric tortuosities between two points defined as the ratio of the geodesic distance (length of the shortest path following the support surface) and the Euclidean distance (length of the straight path) between them. This is a two-step calculation. First, M-coefficients are computed as the harmonic mean of the geometric tortuosities weighted by the inverse of the geodesic distances. Secondly, M-scalar, global tortuosity descriptor, is calculated as the harmonic mean of the M-coefficients weighted by the inverse of the Euclidean distance to the center of mass of the considered volume. $\sigma_{\mathrm{C}}$ is an indicator of confidence in the M-scalar value and is defined as twice the standard deviation of the Mcoefficients divided by the square root of the number of points. The set of points upon which these operators were calculated was either the segmented model's own NP positions or a set of up to 200 points with uniform density of points, called a stratified distribution.

In situ experiments. A Protochips Atmosphere set up (in situ holder, gas manifold, heating system) was used for the TEM in situ reduction experiments. A suspension of powdered sample in ethanol $(1 \mu \mathrm{L})$ was deposited on the sample supporting chip, consisting of a SiC chip with six holes covered by an electron-transparent thin SiN membrane that is then mounted on the in situ holder. After insertion of the holder in the microscope column and checking for leaks, the system is purged 3 times with Ar (back fill pressure 300 torr) then left overnight under Ar flow $\left(0.2 \mathrm{~cm}^{3} / \mathrm{min}\right.$ and pressure of 50 torr $)$ in order to remove the residual $\mathrm{H}_{2} \mathrm{O}$ molecules and/or the residual air content. The reduction thermal treatment is realized under atmospheric pressure (760 torr) with a gas flow of $0.1 \mathrm{~cm}^{3} / \mathrm{min}$ as follows (Figure 1): heating to $200^{\circ} \mathrm{C}$ at $5^{\circ} \mathrm{C} / \mathrm{min}$ under Ar to choose the zones for imaging (1); heating to $520^{\circ} \mathrm{C}$ at $5^{\circ} \mathrm{C} / \mathrm{min}$ under dry air and left for $30 \mathrm{~min}$ (pre-calcination, 2); cooling to $200^{\circ} \mathrm{C}$ under $\mathrm{Ar}(3)$; heating to $500^{\circ} \mathrm{C}$ at $5^{\circ} \mathrm{C} / \mathrm{min}$ under $\mathrm{H}_{2}$ and left for $120 \mathrm{~min}$ (reduction, 4); further heating to $600^{\circ} \mathrm{C}$ and up to $700^{\circ} \mathrm{C}$ to check nanoparticle stability (5). These different steps aim at mimicking the ex situ catalysts reduction procedure. Non imaged zones during the in situ treatment were also analyzed at the end of the treatment to check that identical states are recovered which confirms that no beam effect has occurred.

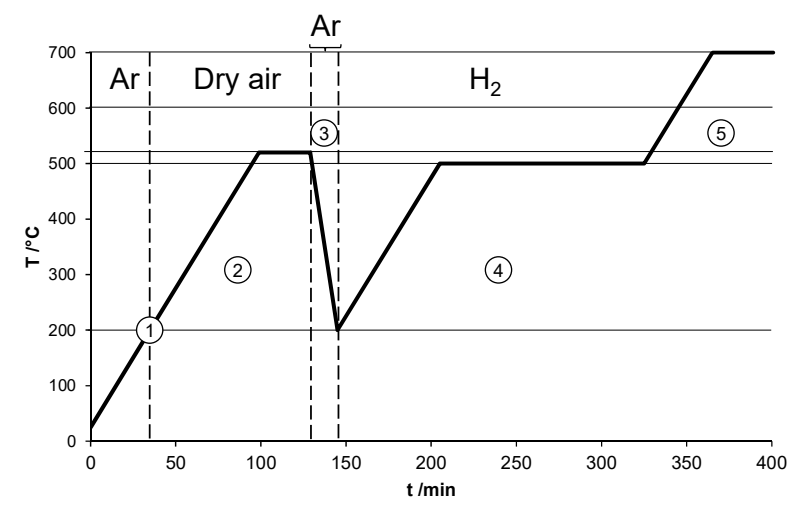

Figure 1. Treatment sequence used during the in situ reduction experiments. Numbers 1 to 5 indicate the stages described in the text.

DFT calculations. $\mathrm{Pt}_{13}$ supported on $\gamma-\mathrm{Al}_{2} \mathrm{O}_{3}$ was modeled using the PBE-dDsC exchange correlation functional ${ }^{61,62}$ and PAW pseudopotentials ${ }^{63}$ with an energy cut off of $400 \mathrm{eV}$ using the VASP code. ${ }^{64,65}$ The criterion for the convergence of the self-consistent cycles was fixed to $10^{-7} \mathrm{eV}$. Geometry optimizations were performed with a convergence criterion on forces of $0.01 \mathrm{eV} \AA^{-1}$. The $\mathrm{Pt}_{13} /(100) \gamma-\mathrm{Al}_{2} \mathrm{O}_{3}$ surface (dehydrated) and $\mathrm{Pt}_{13} /(110)$ surface $\left(11.8 \mathrm{OH} / \mathrm{nm}^{2}\right)$ models previously reported by Mager-Maury et al. ${ }^{53}$ were considered as references and were re-optimized as described above. $\mathrm{Pt}_{13} \mathrm{NPs}$ with the same initial morphology as in the $\mathrm{Pt}_{13} /(100)$ model were deposited in a similar position on the (100) side (near edge) of the (110)-(100) $\gamma-\mathrm{Al}_{2} \mathrm{O}_{3}$ hydrated or chlorinated edge model or right at the edge sites (see S.I. 1.) ${ }^{66}$ and then optimized. This edge model was established recently and consists of a nanorod resulting from cleaving the $\gamma-\mathrm{Al}_{2} \mathrm{O}_{3}$ bulk ${ }^{67}$ in the directions perpendicular to the (110) and the (100) surfaces. It includes two edge terminations, the Al-side exposing $\mathrm{Al}$ atoms and the $\mathrm{O}$-side exposing $\mathrm{O}$ atoms. Here two hydration degrees were considered: $1 \mathrm{H}_{2} \mathrm{O}$ molecule per edge cell and six $\mathrm{H}_{2} \mathrm{O}$ molecules per edge cell (saturated edge sites and hydrated (110) side). The chlorinated edge models are obtained by exchanging either one or both the terminal hydroxyls on the Al-side with $\mathrm{Cl}^{66}{ }^{66}$ To determine the stability of the $\mathrm{Pt}_{13} \mathrm{NP}$, its binding energy $\left(\mathrm{E}_{b}\right.$, in $\mathrm{kJ} / \mathrm{mol}$ per Pt atom) on a given substrate (subs = surface or edge) was calculated according to Equation 1, where $\mathrm{E}\left(\mathrm{Pt}_{1}\right)$ is the energy of a single $\mathrm{Pt}$ atom in the center of a $20 \times 20 \times 20 \AA^{3}$ cell in vacuum.

$\mathrm{E}_{b}\left(\mathrm{Pt}_{13}-s u b s\right)=$

$\left[\mathrm{E}\left(\mathrm{Pt}_{13}-s u b s\right)-\mathrm{E}(s u b s)-13 \mathrm{E}\left(\mathrm{Pt}_{1}\right)\right] / 13$

Eq. 1 

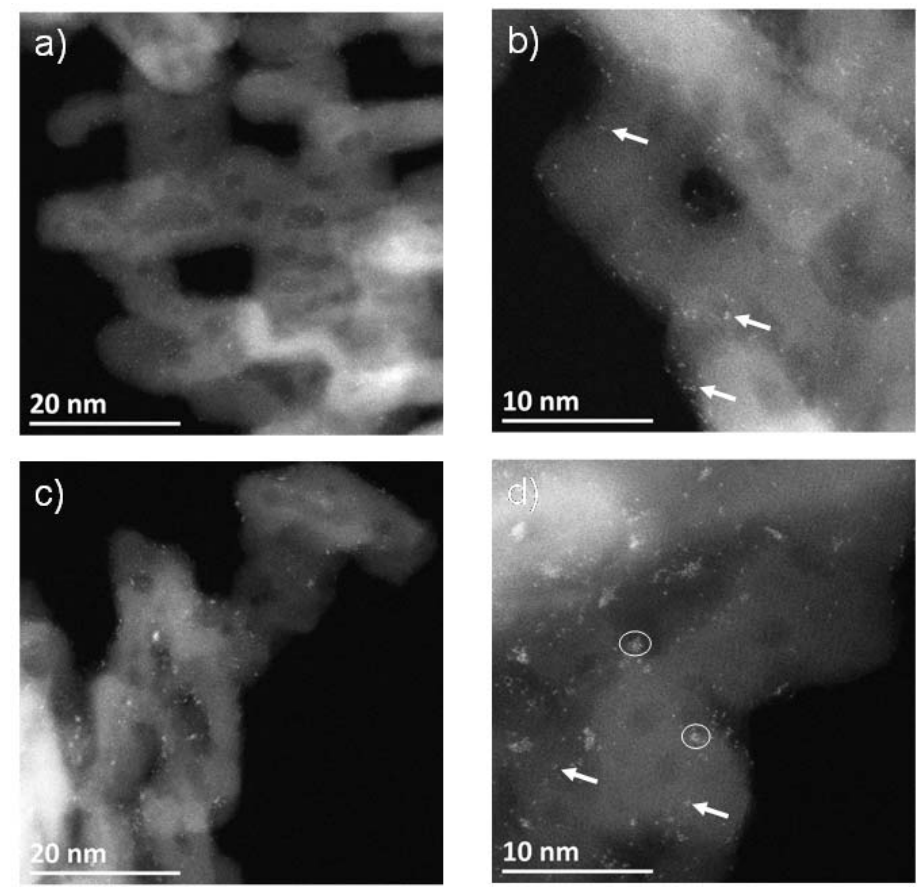

Figure 2. HR-HAADF-STEM images of oxide catalysts a), b) $0.3 \% \mathrm{Pt} / \gamma-\mathrm{Al}_{2} \mathrm{O}_{3}-\mathrm{Cl}$ and c), d) $1 \% \mathrm{Pt} / \gamma-\mathrm{Al}_{2} \mathrm{O}_{3}-\mathrm{Cl}$. White arrows highlight some single atoms. Some clusters composed of more than 5 atoms are circled in white in d).
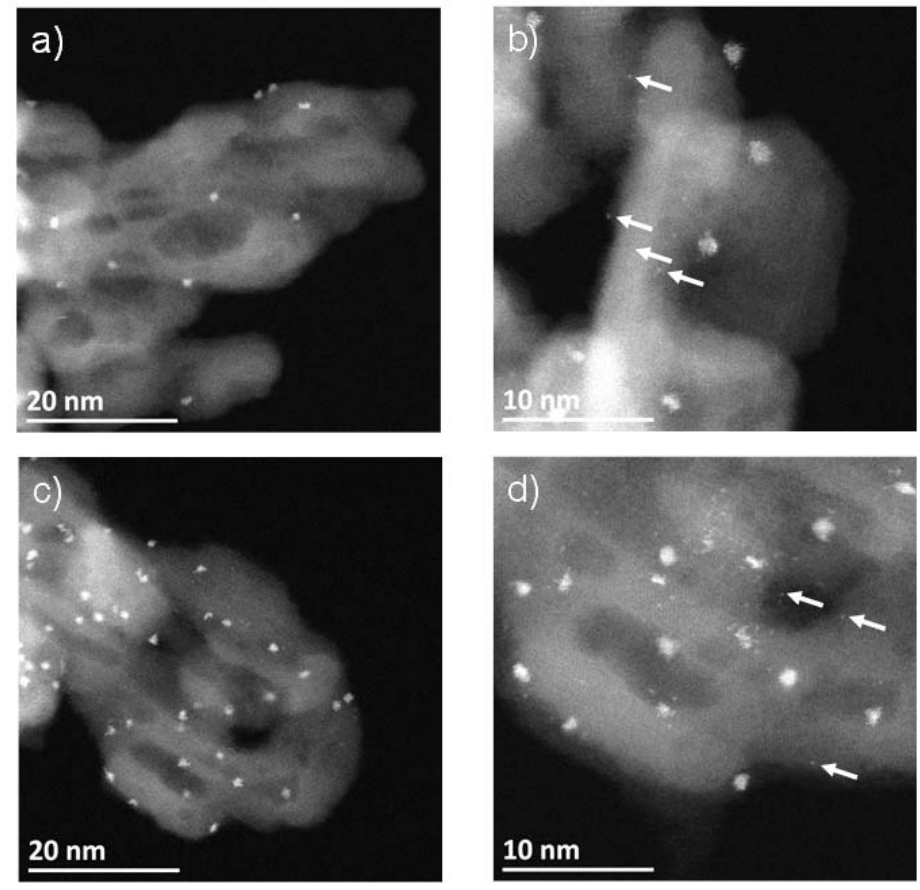

Figure 3. HR-HAADF-STEM images of reduced catalysts a), b) $0.3 \% \mathrm{Pt} / \gamma-\mathrm{Al}_{2} \mathrm{O}_{3}-\mathrm{Cl}$ and c), d) $1 \% \mathrm{Pt} / \gamma-\mathrm{Al}_{2} \mathrm{O}_{3}$-Cl. White arrows highlight some single atoms.

EXAFS experiments. EXAFS spectra were acquired at the FAME-UHD beamline ${ }^{68}$ at the ESRF (Grenoble, France). Experiments were performed at the $\mathrm{Pt} \mathrm{L}_{3}$ edge in fluorescence mode using a multi-crystal analyzer composed of Ge (110) crystals and a mono-element silicon drift detector. A Helium bag was placed between the sample, the crystals and the detector to prevent signal intensity loss by absorption of the (fluo- rescence emitted) X-rays by air molecules. The beam energy was calibrated with Pt foil (first maximum of the first derivative XANES spectrum of the Pt metallic foil was set to 11564 $\mathrm{eV})$. The grinded oxide catalyst samples were packed in quartz Mark-tubes (10 $\mu \mathrm{m}$ wall thickness) for acquisition. Catalysts previously reduced and transported on sealed ampoules under vacuum were re-reduced at atmospheric pressure in a dedicat- 
ed reactor ${ }^{69}$ at $500^{\circ} \mathrm{C}$ under a $10 \mathrm{~mL} / \mathrm{min}$ flow rate of pure $\mathrm{H}_{2}$ $(>99.9999 \%)$. Reference compounds were platinum oxide $\mathrm{PtO}_{2}$ (Sigma-Aldrich, purity $>99.9 \%$, CAS Number 52785-065) and metallic platinum powder (Strem Chemicals, purity $>99.9 \%$, CAS Number 7440-06-4). Data were processed and EXAFS spectra were fitted using Athena and Artemis, respectively, from the Demeter 0.9 .26 software package. ${ }^{70}$ The EXAFS spectra of references $\mathrm{PtO}_{2}$ and $\mathrm{Pt}$ powder were used to obtain $\mathrm{S}_{0}^{2}$ and $\Delta \mathrm{E}_{0}$ (see SI.2).

\section{RESULTS and DISCUSSION}

Characterization of the oxide catalysts. The supported metal oxide created during the calcination in the presence of chlorine is presumed to consist of a $\mathrm{PtCl}_{\mathrm{x}} \mathrm{O}_{\mathrm{y}}$ species, $\mathrm{PtCl}_{4} \mathrm{O}_{2}$ having been suggested in previous studies. ${ }^{52,71}$ Indeed, no Pt neighbors could be fitted to the EXAFS spectra (Table S1). For both oxide catalysts (with $0.3 \%$ and $1 \%$ Pt loading) the coordination number of Pt with the oxygen neighbor atoms at a distance of $2.00 \AA$ is about 3 , and for the $\mathrm{Cl}$ neighbor atoms at a distance of $2.31 \AA$ the coordination number is about 2 .

Typical HR-HAADF-STEM images of both oxide catalysts are shown in Figure 2. Overall, platinum is well dispersed and seems uniformly distributed over the support. At $0.3 \% \mathrm{Pt}$ loading, there are mostly single atoms while some dimers and trimers are also observed, as reported on similar systems. ${ }^{12,18}$ On the observed regions, clusters of more than 5 atoms were rare. For the higher loading of $1 \% \mathrm{Pt}$ however, single atoms, small groups of less than $5 \mathrm{Pt}$ atoms and weakly cohesive clusters with more than 5 atoms are visible. These clusters often appear elongated and for some of them it is hard to determine if a given atom is part of the cluster or not. Since they do present ill-defined structures, the determination of size histogram for these oxide clusters was not possible.

Assuming that there is a given number of anchoring sites for the platinum precursor on the surface of the support, the presence of $\mathrm{Pt}_{\mathrm{n}>5}$ clusters at higher loading suggests that for $0.3 \% \mathrm{Pt}$ there is at most one $\mathrm{Pt}$ atom per occupied site, stabilized by $\mathrm{Cl}$ and $\mathrm{O}$ coordination, while for $1 \% \mathrm{Pt}$ such sites should be saturated, causing subsequent $\mathrm{Pt}$ atoms to coalesce and form the observed oxide clusters.

Characterization of the reduced catalysts. The HRHAADF-STEM images (Figure 3) for the same two catalysts, now after ex situ reduction at $500^{\circ} \mathrm{C}$, are presented. Platinum is still nicely dispersed, now in the form of well-defined nanoparticles (NPs) composed of 10 to 20 atoms. In both cases the average NP size is of about $0.9 \mathrm{~nm}$ and the size histograms (Figure 4) for both samples are similar, showing that $75 \%$ of measured NPs are in the 0.6-1.2 nm range. Thus, the catalyst preparation and reduction protocols consistently enable the genesis of Pt NPs with homogeneous size, whatever the Pt loading. This is confirmed by EXAFS data, as a Pt-Pt coordination number of 3 is obtained for both reduced catalysts (Table S2). At the same time, at iso-NP-size, the increase of $\mathrm{Pt}$ loading simply results in the increased number of Pt NPs.

The NPs were found to have a flat bi-planar morphology through HAADF intensity analysis (Figure 5), as the "atomic columns" aligned perpendicularly to the electron beam in the studied NPs are composed of at most $2 \mathrm{Pt}$ atoms. The analysis was cautiously performed using relevant images obtained before the beam interaction caused the atoms in the NPs to move. This bi-planar morphology is fully compatible with the previously found by DFT studies of $\mathrm{Pt}_{13}$ clusters on the (100) alumina surface. ${ }^{21}$ Other microscopy analyses also referred to such nanoparticles as "raft-like". 12,13

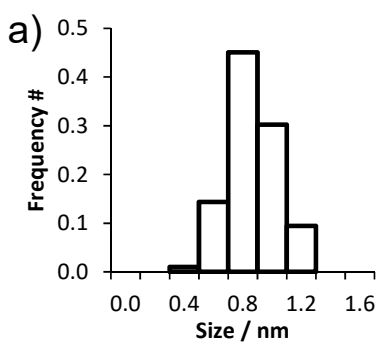

Mean: $0.86 \mathrm{~nm} n=202$ Std. Deviation: $0.16 \mathrm{~nm}$

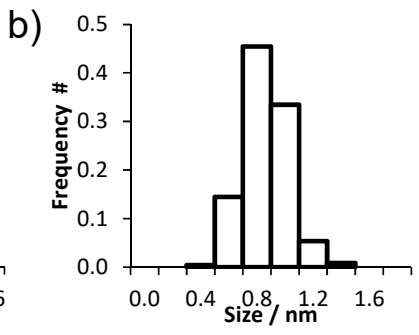
Std. Deviation: $0.15 \mathrm{~nm}$
Mean: $0.86 \mathrm{~nm} \mathrm{n}=242$

Figure 4. Nanoparticle size histograms obtained for reduced a) $0.3 \% \mathrm{Pt} / \gamma-\mathrm{Al}_{2} \mathrm{O}_{3}-\mathrm{Cl}$ and b) $1 \% \mathrm{Pt} / \gamma-\mathrm{Al}_{2} \mathrm{O}_{3}-\mathrm{Cl}$.
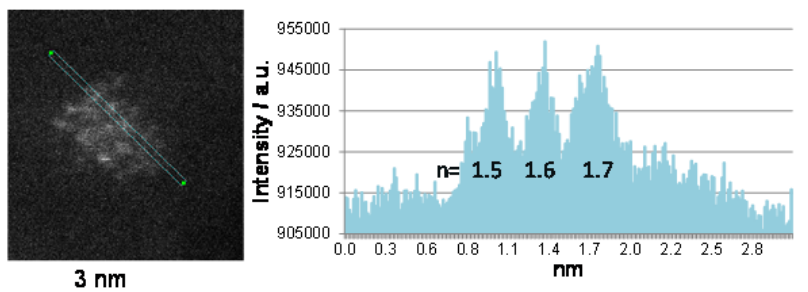

Figure 5. HAADF intensity profile and respective atom column quantification for a nanoparticle belonging to $1 \% \mathrm{Pt} / \gamma-\mathrm{Al}_{2} \mathrm{O}_{3}-\mathrm{Cl}$.

Lastly, single atoms are highlighted and their population was quantified by the ratio "number of SA / number of NP" which is close to 2.8 for the two Pt loadings and the $\mathrm{Cl}$ content considered here. Assuming that each NP is made of about $13 \mathrm{Pt}$ atoms, this would also mean that $20 \%$ of deposited $\mathrm{Pt}$ atoms are engaged in SA.

In situ characterization of the Pt NP genesis. The homogeneous NP size distribution found between the two reduced samples was not expected, considering the observations made for the oxide catalysts, where differing Pt species are present. To gather information on nanoparticle formation, the $1 \% \mathrm{Pt} / \gamma$ $\mathrm{Al}_{2} \mathrm{O}_{3}-\mathrm{Cl}$ catalyst was imaged during reduction using a dedicated in situ holder and set-up. Images obtained at different steps of the treatment are shown in Figure 6, for two analyzed regions. Before reduction, a few of the larger clusters of the oxide sample, such as those described previously, are visible (Figure 6-a), and remains stable until the end of the precalcination (Figure 6-b). Once under $\mathrm{H}_{2}$ and at $500^{\circ} \mathrm{C}$, Pt nanoparticles appear with a better contrast, indicator of the metallic state of NPs (Figure 6-c,d). Even after two hours at $500^{\circ} \mathrm{C}$ under $\mathrm{H}_{2}$, there is no sign of mobility or of coalescence of the nanoparticles A temperature of about $700^{\circ} \mathrm{C}$ is needed to observe the coalescence of some NPs. Similar final states were found in the zones that were not exposed to the beam during the experiment. 


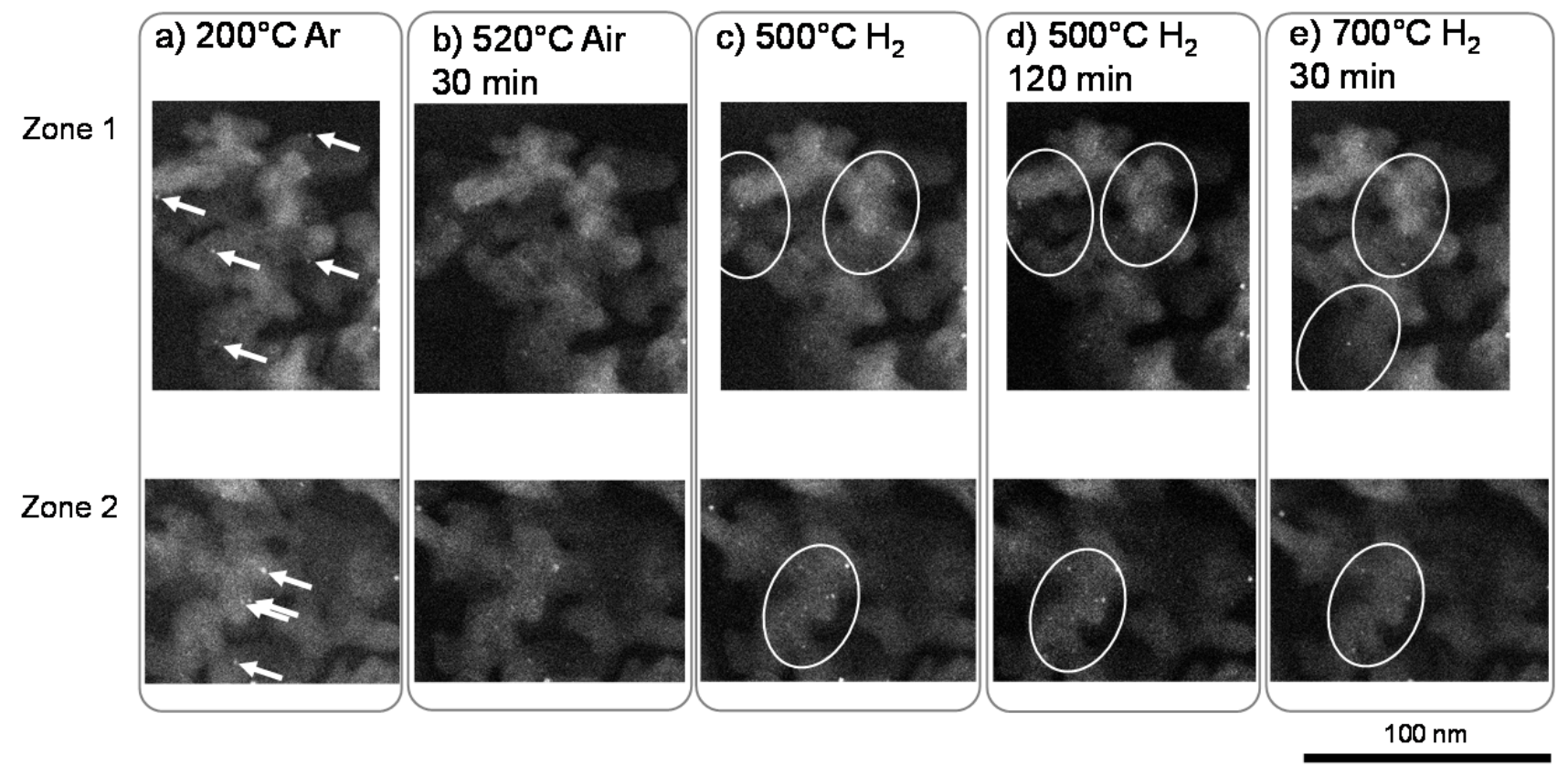

Figure 6. HAADF-STEM images acquired during in-situ reduction of $1 \% \mathrm{Pt} / \gamma-\mathrm{Al}_{2} \mathrm{O}_{3}-\mathrm{Cl}$ in two zones, 1 and 2 , at different moments of the treatment: a) initial state under $\mathrm{Ar}$ at $200^{\circ} \mathrm{C}$, b) at the end of the pre-calcination of 30 minutes under air, c) at $500^{\circ} \mathrm{C}$ under $\mathrm{H}_{2}$ immediately after heating to $500^{\circ} \mathrm{C}$ at $5^{\circ} \mathrm{C} /$ min under $\mathrm{H}_{2}$, d) at the end of the reduction plateau of $2 \mathrm{~h}$ under $\mathrm{H}_{2}$, e) after further heating and 30 min plateau at $700^{\circ} \mathrm{C}$. White arrows indicate clusters already present on the oxide catalysts and white circles highlight regions where changes can be observed.

a)

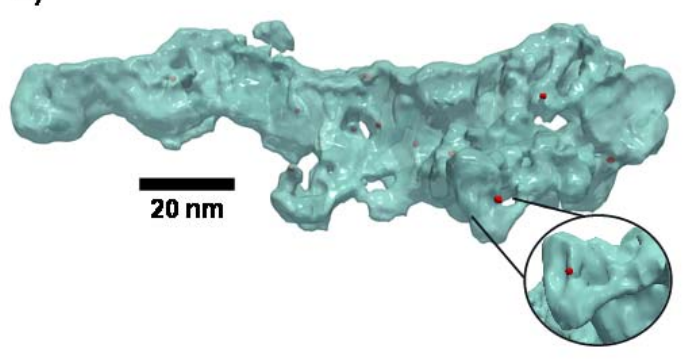

c)

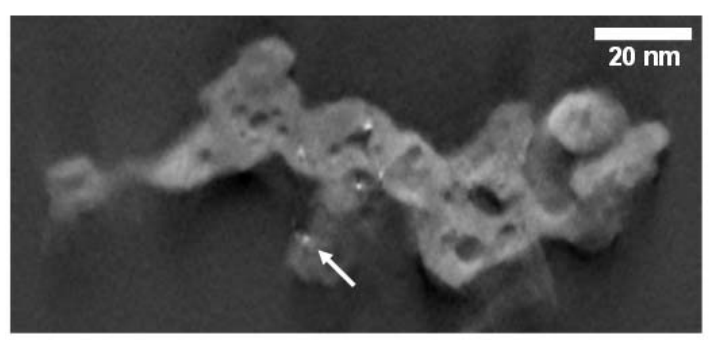

b)

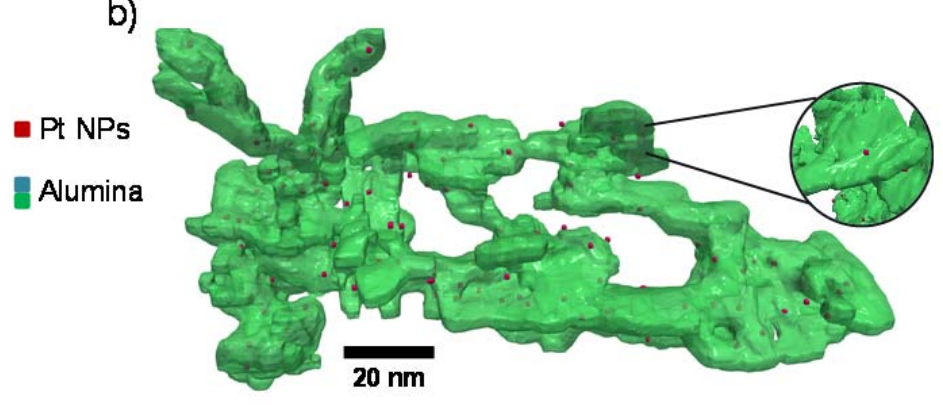

d)

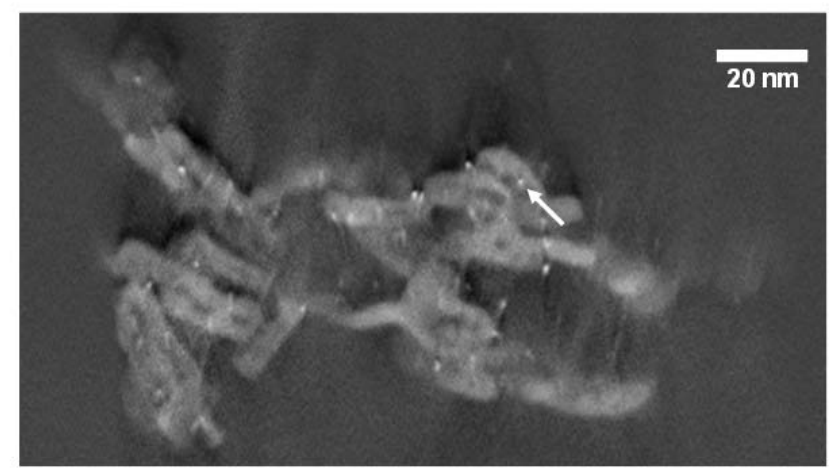

Figure 7. Segmented volumes a) and b) and slice of reconstruction c) and d) obtained from tomographic series of $0.3 \% \mathrm{Pt} / \gamma-\mathrm{Al}_{2} \mathrm{O}_{3}-\mathrm{Cl}$ and of $1 \% \mathrm{Pt} / \gamma-\mathrm{Al}_{2} \mathrm{O}_{3}-\mathrm{Cl}$ reduced catalysts, respectively, where an example of nanoparticle located on the alumina crystallite edge is highlighted in the segmentation and indicated by a white arrow in the reconstruction slice. 


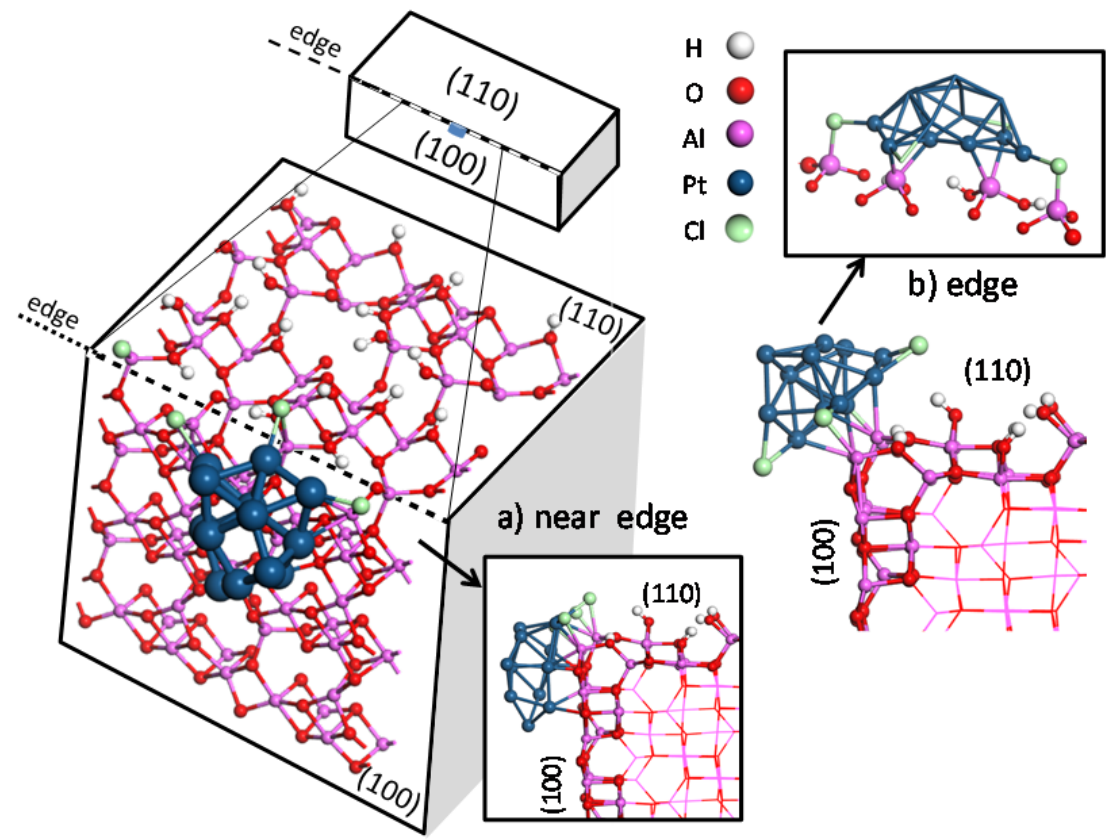

Figure 8. Alumina platelet scheme and two most stable $\mathrm{Pt}_{13}$ /edge-Cl model with the NP on the chlorinated Al-side (110)-(100) edge highlighted by the broken line for a) near edge configuration $\mathrm{E}$ and b) edge configuration $\mathrm{A}$ (see $\mathrm{SI}$ ) .

During the in situ experiment the signal to noise ratio of the HAADF image intensity is not as good as in the conventional (under vacuum) TEM mode, because of the additional electron diffusion effect provided by the $\mathrm{SiC}$ chip membranes and of the gas in the samples holder. Moreover high magnification observations are not used to avoid beam damages. Thus, resolution is decreased and this means Pt single atoms, abundant in the oxide catalyst and also found in the reduced one, cannot be observed. As the NPs become visible during reduction, without any mobility of the original oxide clusters nor of the newly formed NPs, the single atoms are expected to play a role on the NP formation mechanism as recently suggested. ${ }^{18}$

Location of Pt NPs. HAADF-STEM electron tomography results are presented in Figure 7 which shows one 3D segmented volume for each catalyst. Two other volumes are shown in Figure S4. Note that the Pt single atoms are below the resolution of this technique. With these volumes, it is possible to assess what is the preferred location of NPs on the support crystallites. This was done by assessing manually the location of several NPs on the volumes. Because this is a very time-consuming protocol, not all visible NPs in the volumes were considered in the data analysis protocol. The procedure employed for the reduction of the number of NPs for which the data analysis protocol was applied is reported in supporting information S.I.3.

For the $0.3 \% \mathrm{Pt} / \gamma-\mathrm{Al}_{2} \mathrm{O}_{3}-\mathrm{Cl}$ reduced catalyst, the two reconstructed objects present a total of 43 NPs. The NP location with respect to the surface of the support crystallite was attempted for $25 \mathrm{NPs}$, and unambiguously assessed visually for 22 of these ( 3 have undetermined positions due to a bad definition of the contours obtained segmentation, see Table S3 in supporting information S.I.3). Out of those, 18 are located on the crystallites edges (as represented in inset of Figure 7) or other defaults (steps or kinks) and 4 are located on crystallite planes. For the $1 \% \mathrm{Pt} / \gamma-\mathrm{Al}_{2} \mathrm{O}_{3}-\mathrm{Cl}$ reduced catalyst, there are 186 NPs in the two reconstructed objects. Again, NP location on the crystallite surface data analysis protocol was attempted for 79 NPs and unambiguously assigned for 58 of these. Out of those, 45 were found to be located on the crystallites edges (inset of Figure 7) or other defaults and 13 were found to be located on crystallite planes.

Considering the data reported in Table S3 of S.I. for the two samples, the present electron tomography analysis shows that Pt nanoparticles on industry relevant catalysts are preferably located on crystallite edges or edge-like defaults (steps and kinks). Indeed, including the uncertainties induced by the NPs for which a $3 \mathrm{D}$ position was deduced by the data analysis protocol but were finally classed as "undetermined" (that may be on edges or on facets), estimated that in the $0.3 \% \mathrm{Pt} / \gamma$ $\mathrm{Al}_{2} \mathrm{O}_{3}-\mathrm{Cl}$ and in the $1 \% \mathrm{Pt} / \gamma-\mathrm{Al}_{2} \mathrm{O}_{3}-\mathrm{Cl}$ samples, the proportion of NPs located on edge or edge-like structures is $78 \pm 6 \%$ and $70 \pm 13 \%$ respectively. It may seem counter-intuitive that the uncertainty is larger for $1 \% \mathrm{Pt} / \gamma-\mathrm{Al}_{2} \mathrm{O}_{3}-\mathrm{Cl}$ for which more NPs were considered in the data analysis protocol. At this regard, we should mention that this uncertainty depends on the number of NPs assigned to the "undetermined" class for which the difficulty in the determination of their exact positions (with respect to the support surface) originates from a quite inaccurate segmentation at the locations characterized by a low signal to noise ratio.

Crystallite edges are thought to harbor strong Lewis sites and highly resistant hydroxyls groups with respect to facets, having potentially a role in alumina surface reactivity. ${ }^{72}$ Indeed, in a recent study, ${ }^{66}$ the first DFT model of alumina (110)-(100) edge was established. This model consists in a nanorod, distinguishing the behavior of "O edges" versus "Al edges" (Figure S1). It was shown by NMR and DFT analysis that hydrox- 
yls located at edges are preferentially exchanged with chlorine.

A first approach to evaluate the Pt NP stability on edges was thus conducted by DFT calculations. Eleven configurations of $\mathrm{Pt}_{13}$ supported on the (110)-(100) edge were considered for two main NP positions: a) a so-called "near-edge" position where the NP interacts with the (100) facet of the nano-rod and with edge atoms; or b) a strictly speaking edge position where the NP interacts uniquely with Al edge atoms.

In the "near edge" case, varying degrees of hydration and chlorination were considered (see S.I. 4.) and the most stable model was obtained for $\mathrm{Pt}_{13}$ on the Al-side of the hydrated (110)-(100) edge with a binding energy of $-409 \mathrm{~kJ} / \mathrm{mol}$ (see configuration B in S.I. 4.). On the Al-side saturated with chlorine (Figure 8 a and configuration $\mathrm{E}$ in S.I. 4), the binding energy is very similar at $-404 \mathrm{~kJ} / \mathrm{mol}$. $\mathrm{Pt}_{13}$ on the $\mathrm{O}$-side of the hydrated (110)-(100) edge exhibits also a similar binding energy of $-403 \mathrm{~kJ} / \mathrm{mol}$ (see configuration $\mathrm{F}$ in S.I. 4.). Note that in spite of the location of the particles at the edge, these models are compatible with the existence of an interaction of Pt with $\mathrm{Al}_{\mathrm{V}}$ atoms as shown by Kwak et al. ${ }^{5}$ Indeed in the models, the platinum particle interacts with edge $\mathrm{Al}$ atoms (mostly distorted $\mathrm{Al}_{\mathrm{IV}}$ ) but also with close-by $\mathrm{Al}_{\mathrm{V}}$ atoms from the (100) facet. In addition, the $\mathrm{Pt}_{13}$ cluster is stabilized by numerous Pt-Al (2.45-2.63 $\AA$ ) and Pt-O (2.12-2.28 $\AA$ ) coordination. Three $\mathrm{Cl}$ atoms are located in a bridging position between $3 \mathrm{Pt}$ atoms and $3 \mathrm{Al}$ edge sites.

In the strictly speaking edge case, $\mathrm{Pt}_{13}$ is connected uniquely to edge atoms on the $\mathrm{Al}$ side in the presence of chlorine and the most stable model, shown in Figure $8 \mathrm{~b}$ (and configuration A in S.I. 4.), exhibits a binding energy of $-414 \mathrm{~kJ} / \mathrm{mol}$. This is the most sable structure obtained in this study. The stability of this configuration is ensured on the one hand by two $\mathrm{Al}$ edge sites in hollow positions below two $\mathrm{Pt}_{3}$ trimers of the $\mathrm{Pt}_{13}$ cluster. Hence, four Pt-Al distances (comprised between 2.48 and 2.59 $\AA$ ) remain compatible with the distances measured by EXAFS at 2.41-2.43 $\AA$. No Pt-O distance is found in this region. On the other hand, as in the previous case, two $\mathrm{Cl}$ atoms are bridging two Pt atoms with two other $\mathrm{Al}$ sites.

For the two models depicted in Figure 8 the average Pt-Pt coordination number (considering only the bonds under $3 \AA$ ) is 4.2 and the average Pt-Pt distance is $2.6 \AA$, which is compatible with the EXAFS results for the reduced catalysts (Table S2).

Considering the possible locations on the (100) and (110) surfaces of alumina, the binding energies recalculated by using the PBE-dDsC functional, for the previously published mod$\mathrm{els}^{53}$ of $\mathrm{Pt}_{13} /(100)$ surface (dehydrated) and $\mathrm{Pt}_{13} /(110)$ surface (with $11.8 \mathrm{OH} / \mathrm{nm}^{2}$ ) are $-416 \mathrm{~kJ} / \mathrm{mol}$ and $-397 \mathrm{~kJ} / \mathrm{mol}$ respectively. Thus, all the configurations simulated on edges are as stable as the $\mathrm{Pt}_{13} /$ surface models, indicating that within the DFT accuracy $(\sim 10-20 \mathrm{~kJ} / \mathrm{mol})$ the edge and near edge NP location competes with location on alumina facets. According to our previous work, ${ }^{66}$ the chlorine exchange step is thermodynamically more favored at edge than on the surfaces. Due to the position of $\mathrm{Cl}$ atoms in close vicinity at edge (Figure 8), we cannot exclude the existence of some direct $\mathrm{Pt}-\mathrm{Cl}$ bonds, which cannot be measured by EXAFS due to the very low Pt$\mathrm{Cl}$ coordination number expected from the DFT model (between 0.2 and 0.5 ). Moreover, the formation of Pt NP at such location might be enhanced by a synergy effect with chlorine stabilization. Investigating this aspect remains beyond the scope of the present work and requires a dedicated study of the formation mechanisms of the Pt NP on chlorinated alumina.

Inter-NP distance. Qualitatively the HAADF-STEM images in Figure 3 suggest that for $1 \% \mathrm{Pt}$ the NPs are closer to each other, as they are more numerous than for $0.3 \% \mathrm{Pt}$. Preferential location of Pt NPs on crystallites edges has been highlighted by electron tomography. In what follows, we propose an original method to calculate interparticle distance from 3D models obtained by electron tomography.

By means of the dedicated geometrical analysis, the geodesic distances between NPs following the support surface can be quantified and the support tortuosity assessed as a method for solving the NP dispersion at the surface qualification, from electron tomography. A previous electron tomography study of CuZn particles of sizes greater than $4 \mathrm{~nm}$, supported on ordered mesoporous silica allowed to evaluate the mean distance between particles in well-defined and periodically ranged pores. ${ }^{73}$ However, in the case at hand, this analysis is far less straightforward, due to the tortuosity of the $\gamma$-alumina's porosity which requires a specific mathematic treatment of the tomography images to extract the geodesic distance between NPs. Figure 9 reports the histograms of the distance of each NP to its closest neighbor for the two catalyst samples. The inter-NP distances are obviously tuned by the $\mathrm{Pt}$ loading: for the lowest loading the average value being $9 \mathrm{~nm}$ whereas it is $16 \mathrm{~nm}$ for the highest one.

The mean geometric tortuosity (see Experimental Section and Methods) calculated for the segmented images shown in Figure 7 was also determined and analyzed. To identify if the Pt NPs are located on a specific pore region of the support, the tortuosity descriptors are calculated to evaluate the nanoparticles distribution through the segmented object using either the NP positions or uniform density sampled points set. The histograms of mean geometric tortuosity (Figure 10) obtained using the NP positions are consistently concentrated over the most frequent values obtained using the point set. The statistic impact of number of points is clear, as for $0.3 \% \mathrm{Pt} / \gamma-\mathrm{Al}_{2} \mathrm{O}_{3}-\mathrm{Cl}$ there are fewer NPs in the object than for $1 \% \mathrm{Pt} / \gamma-\mathrm{Al}_{2} \mathrm{O}_{3}-\mathrm{Cl}$, a much better match is obtained for $1 \% \mathrm{Pt} / \gamma-\mathrm{Al}_{2} \mathrm{O}_{3}-\mathrm{Cl}$. Considering the resulting M-scalar descriptor (Table S6 of S.I.), it appears that the M-scalar values ( 1.2) are remarkably similar for both NP positions and the point set. For NP positions the impact of using fewer points in the case of $0.3 \% \mathrm{Pt} \gamma-\mathrm{Al}_{2} \mathrm{O}_{3}-\mathrm{Cl}$ is highlighted by higher $\sigma_{\mathrm{C}}$ values $(0.07$ vs 0.02$)$. Overall, the mean geometric tortuosity evaluation of the alumina support is very similar for the point set and the Pt NP positions themselves, revealing that the nanoparticles are uniformly distributed in the alumina support's aggregates, which are made of individual alumina crystallites, as opposed to being concentrated in a given region. 


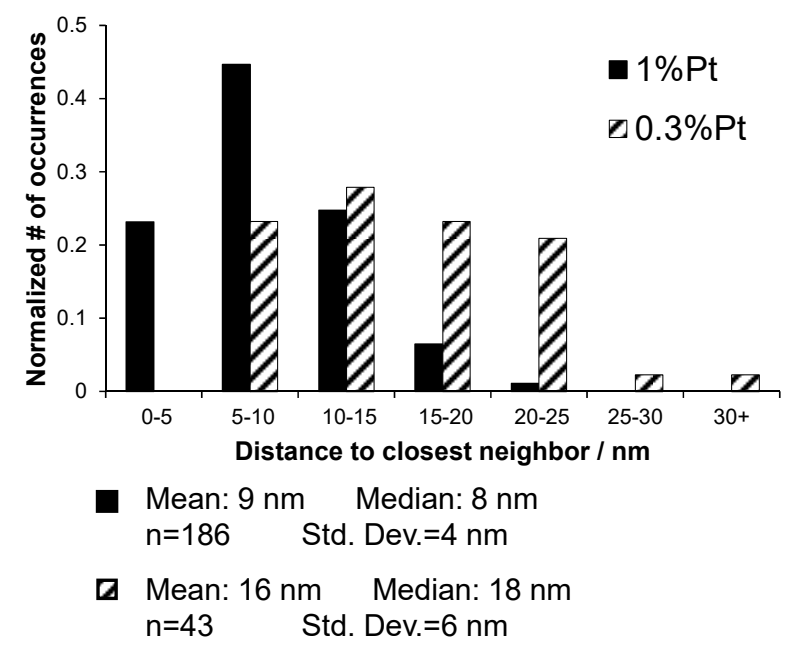

Figure 9. Histogram for the geodesic distance following the support surface between a given nanoparticle and its closest nanoparticle neighbor obtained from both segmented objects of each catalyst, $1 \% \mathrm{Pt} / \gamma-\mathrm{Al}_{2} \mathrm{O}_{3}-\mathrm{Cl}$ in full black and $0.3 \% \mathrm{Pt} / \gamma-\mathrm{Al}_{2} \mathrm{O}_{3}-\mathrm{Cl}$ in stripes.

a) $0.3 \% \mathrm{Pt} / \mathrm{Y}-\mathrm{Al}_{2} \mathrm{O}_{3}-\mathrm{Cl}$ reduced

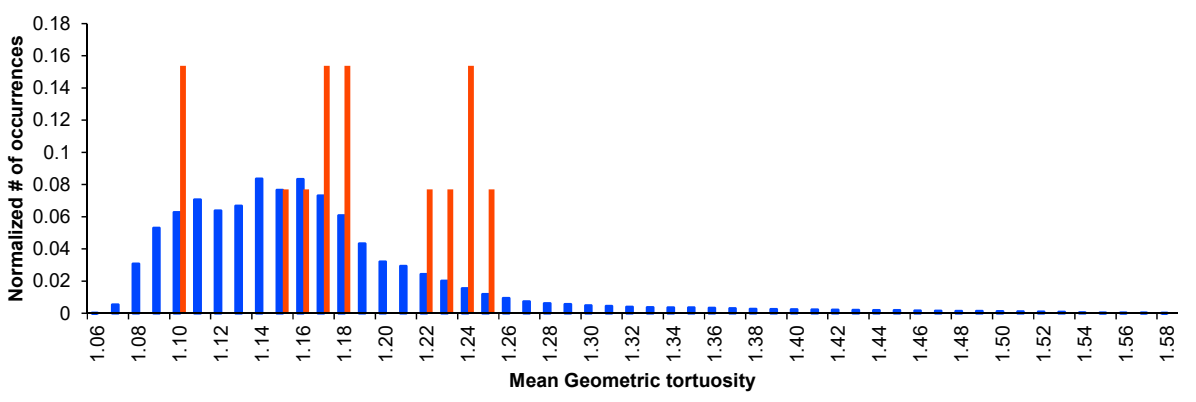

b) $1 \% \mathrm{Pt} / \mathrm{Y}-\mathrm{Al}_{2} \mathrm{O}_{3}-\mathrm{Cl}$ reduced

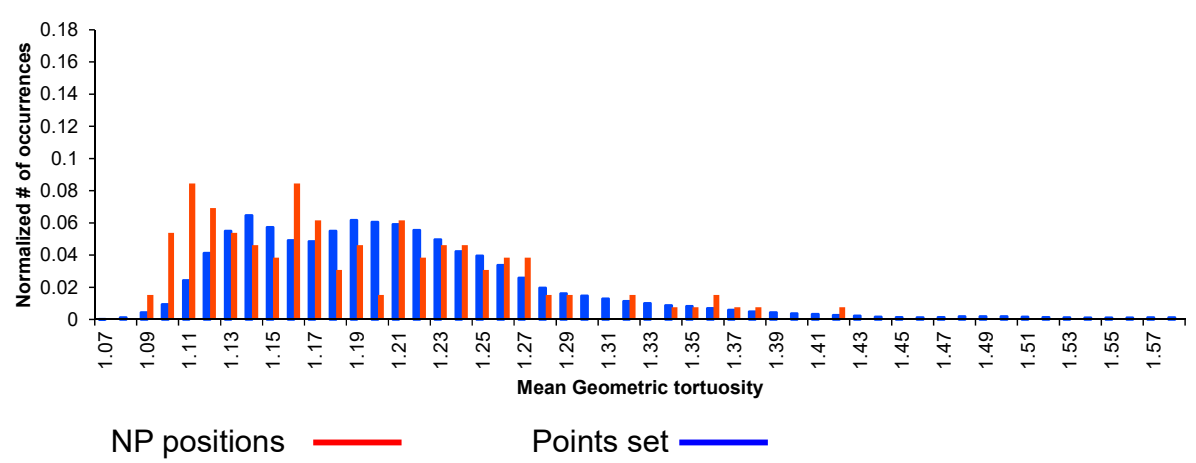

Figure 10. Comparison of normalized mean geometric tortuosity histograms obtained using the NP positions (red) or the 200 points set (blue) for the segmented object presented in Figure 7 of each reduced catalyst, a) $0.3 \% \mathrm{Pt} / \gamma-\mathrm{Al}_{2} \mathrm{O}_{3}-\mathrm{Cl}$ and b) $1 \% \mathrm{Pt} / \gamma-\mathrm{Al}_{2} \mathrm{O}_{3}-\mathrm{Cl}$.

To figure out the Pt NPs distribution on the alumina support, a geometric model, illustrated in Figure 11, was built on the following assumptions: a) support crystallites are of a parallelepipedic morphology with the average size of about 4 x $14.5 \mathrm{x}$ $9 \mathrm{~nm}$ as estimated from TEM images ${ }^{66}$; b) all Pt atoms are engaged in $\mathrm{Pt}_{13}$ NPs (as analyzed in Figure 3 or invoked in several DFT studies ${ }^{7,18,21,53}$ corresponding to a size of $0.9 \mathrm{~nm}$, better representing our samples); c) Pt NPs are distributed in a square network. For a $1 \%_{\mathrm{w} / \mathrm{w}} \mathrm{Pt}$ loading, the distance between
Pt NPs in a square network is found to be of $9.5 \mathrm{~nm}$, while for $0.3 \%_{\mathrm{w} / \mathrm{w}} \mathrm{Pt}$, the distance is of $17.3 \mathrm{~nm}$. If the distribution of $\mathrm{Pt}$ on an alumina crystallite is now considered, for $1 \% \mathrm{Pt}$ there would be about 5 NPs per crystallite whereas for $0.3 \%$ Pt there would be only one single NP per crystallite. As the STEM images suggest, this geometric model indicates that the two Pt loadings have an impact on the distance between NPs, which can be either intra- or inter- alumina crystallite. The mean inter-NP geodesic distance obtained from the tomographic 
volumes (Figure 9) is in remarkable agreement with those given by the simple geometric model (Figure 11): $9 \mathrm{~nm}$ for $0.3 \% \mathrm{Pt}$ and $16 \mathrm{~nm}$ for $1 \% \mathrm{Pt}$. This implies that, for these loadings, anchoring sites for NPs are abundant enough and lead to a uniform random distribution of inter-NP distances close to that of a distribution of a uniform density of sample points. Since numerous catalytic processes such as naphtha reforming are strongly exposed to deactivation by NP sintering, we expect from such a uniform distribution to minimize the number of Pt NP per alumina platelet to provide thus an optimal configuration for avoiding the growth of Pt NP during the catalyst's life cycle. This beneficial effect has been invoked in methanol synthesis for $\mathrm{CuZn}$ particles with maximal interparticle distance on mesoporous silica support. ${ }^{73}$
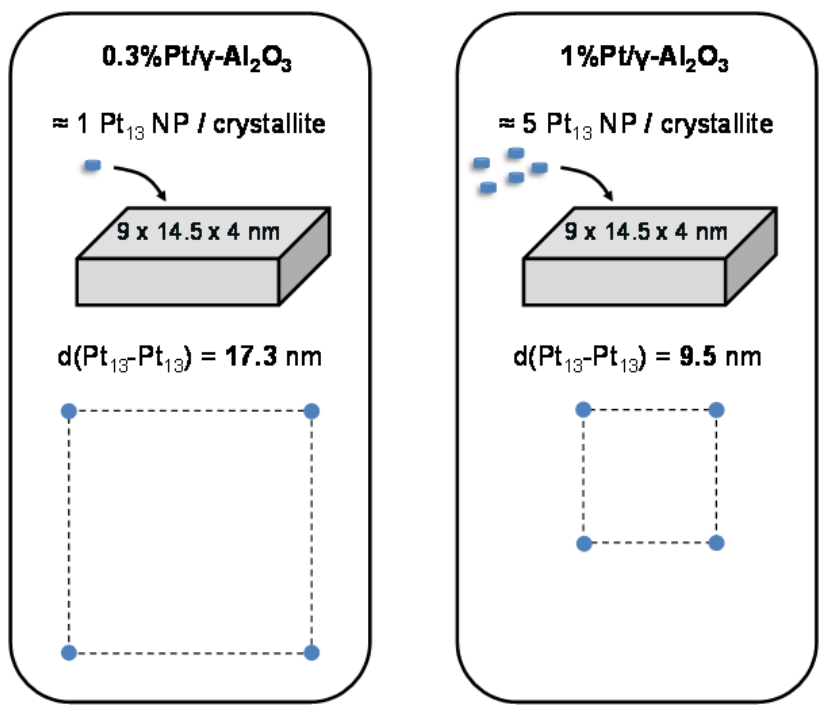

Figure 11. Illustration of the impact of platinum loading on interNP distance predicted by a square network geometric model.

\section{CONCLUSION}

On industry relevant catalysts with low Pt loadings (close to and smaller than $1 \%_{\mathrm{w} / \mathrm{w}} \mathrm{Pt}$ ) supported on high surface $\gamma$ alumina, once reduced, Pt is dispersed as flat NPs of $0.9 \mathrm{~nm}$ and scattered single atoms. The tomographic study showed for the first time that these NPs are located mostly on the edges of the crystallites and are uniformly distributed through the support aggregate. DFT calculations indicated that such edge or near edge locations are thermodynamically as favorable as the surfaces. The role of chlorine to stabilize Pt NP at edges may be suspected, however this should be the matter of future investigations devoted to the mechanisms of Pt NP formation on chlorinated alumina. As demonstrated before, the chlorination of $\gamma$-alumina may be tuned by the morphology and the proportion of edges on the $\gamma$-alumina nano-crystallites. ${ }^{66} \mathrm{At}$ this regard, it would be interesting in future studies to investigate how the location, the number of Pt particles or Pt single atoms per alumina crystallite and the Pt interparticle distance may be finely tuned by the choice of the $\gamma$-alumina morphologies, chlorine content and Pt loading.

The average distance between NPs was quantified from the 3D tomography volumes and is fully compatible with a geometric model, showing that this distance between NPs is tuned through Pt loading and may be shifted from intra- to interalumina crystallite for $1 \%_{\mathrm{w} / \mathrm{w}} \mathrm{Pt}$ to $0.3 \%_{\mathrm{w} / \mathrm{w}} \mathrm{Pt}$. We expect that this trend may impact the behavior of bifunctional catalysts. The NPs are very stable and show no mobility during the reduction treatment under $\mathrm{H}_{2}$ at $500^{\circ} \mathrm{C}$. Their formation mechanism is expected to depend on the coalescence of single atoms which are abundant in the initial oxide state of the catalysts and are still present in the reduced catalysts. Gaining further insights on the genesis of NPs will depend on the future improvements of the experimental analysis conditions in the in situ TEM mode in an environmental gas cell.

\section{AUTHOR INFORMATION}

\section{Corresponding Authors}

*pascal.raybaud@ifpen.fr

*ovidiu.ersen@ipcms.unistra.fr

\section{Author Contributions}

All authors have given approval to the final version of the manuscript.

\section{Funding Sources}

This work was funded by IFPEN and supported by the LCR "CARactérisation des Matériaux pour l'Energie" (CARMEN). The FAME-UHD project is financially supported by the French "grand emprunt"/"large loan" EquipEx (EcoX, ANR-10-EQPX27-01), the CEA-CNRS CRG consortium and the INSU CNRS institute.

\section{ASSOCIATED CONTENT}

Supporting Information. EXAFS data and fittings; Edge models; $\mathrm{Pt}_{13}$ /edge models and their binding energies; M-tortuosity values. This material is available free of charge via the Internet at http://pubs.acs.org.

\section{ACKNOWLEDGMENTS}

G. Melinte is acknowledged for initial testing of grid preparation and microscope tuning parameters for optimized tomographic series acquisition. E. Rosati is acknowledged for preparing the support extrudates. C. Voisin and C. Guégan are acknowledged for technical assistance for catalysts preparation. Calculations were performed using HPC resources from GENCI-CINES (Grant A0020806134) and from IFP Energies nouvelles.

\section{ABBREVIATIONS}

DFT density functional theory; HAADF high angle annular dark field; NP nanoparticle, SA single atom; STEM scanning transmission electron microscopy; EXAFS Extended x-ray absorption fine structure.

\section{REFERENCES}

(1) Sattler, J. H. B.; Ruiz-Martinez, J.; Santillan-Jimenez, E.; Weckhuysen, B. M. Catalytic Dehydrogenation of Light Alkanes on Metals and Metal Oxides. Chem. Rev. 2014, 114, 10613-10653.

(2) Besson, M.; Gallezot, P.; Pinel, C. Conversion of Biomass into Chemicals over Metal Catalysts. Chem. Rev. 2014, 114, 1827-1870.

(3) Cui, X.; Junge, K.; Dai, X.; Kreyenschulte, C.; Pohl, M.-M.; Wohlrab, S.; Shi, F.; Brückner, A.; Beller, M. Synthesis of Single 
Atom Based Heterogeneous Platinum Catalysts: High Selectivity and Activity for Hydrosilylation Reactions. ACS Cent. Sci. 2017, 3, 580585 .

(4) Oudenhuijzen, M. K.; van Bokhoven, J. A.; Miller, J. T.; Ramaker, D. E.; Koningsberger, D. C. Three-site model for hydrogen adsorption on supported platinum particles: influence of support ionicity and particle size on the hydrogen coverage. J. Am. Chem. Soc. 2005, 127, 1530-1540.

(5) Kwak, J. H.; Hu, J.; Mei, D.; Yi, C.-W.; Kim, D. H.; Peden, C. H. F.; Allard, L. F.; Szanyi, J. Coordinatively unsaturated $\mathrm{Al}^{3+}$ centers as binding sites for active catalyst phases of platinum on gamma$\mathrm{Al}_{2} \mathrm{O}_{3}$. Science 2009, 325, 1670-1673.

(6) Karim, W.; Spreafico, C.; Kleibert, A.; Gobrecht, J.; VandeVondele, J.; Ekinci, Y.; van Bokhoven, J. A. Catalyst support effects on hydrogen spillover. Nature 2017, 541, 68-74

(7) Gorczyca, A.; Moizan, V.; Chizallet, C.; Proux, O.; Del Net, W.; Lahera, E.; Hazemann, J.-L.; Raybaud, P.; Joly, Y. Monitoring morphology and hydrogen coverage of nanometric Pt/gamma- $\mathrm{Al}_{2} \mathrm{O}_{3}$ particles by in situ HERFD-XANES and quantum simulations. Angew. Chem. Int. Ed. 2014, 53, 12426-12429.

(8) Nellist, P. D.; Pennycook, S. J. Direct Imaging of the Atomic Configuration of Ultradispersed Catalysts. Science 1996, 274, 413415.

(9) Szlachetko, J.; Ferri, D.; Marchionni, V.; Kambolis, A.; Safonova, O. V.; Milne, C. J.; Kröcher, O.; Nachtegaal, M.; Sá, J. Subsecond and in Situ Chemical Speciation of $\mathrm{Pt} / \mathrm{Al}_{2} \mathrm{O}_{3}$ during Oxidation-Reduction Cycles Monitored by High-Energy Resolution OffResonant X-ray Spectroscopy. J. Am. Chem. Soc. 2013, 135, 1907119074.

(10) Kovarik, L.; Genc, A.; Wang, C.; Qiu, A.; Peden, C. H. F.; Szanyi, J.; Kwak, J. H. Tomography and High-Resolution Electron Microscopy Study of Surfaces and Porosity in a Plate-like $\gamma-\mathrm{Al}_{2} \mathrm{O}_{3}$. J. Phys. Chem. C 2013, 117, 179-186.

(11) M. Boudart. Catalysis by Supported Metals. Adv. Catal. 1969, 20, 153-166.

(12) Bradley, S. A.; Sinkler, W.; Blom, D. A.; Bigelow, W.; Voyles, P. M.; Allard, L. F. Behavior of Pt Atoms on Oxide Supports During Reduction Treatments at Elevated Temperatures, Characterized by Aberration Corrected Stem Imaging. Catal. Lett. 2012, 142, 176-182.

(13) Sinkler, W.; Sanchez, S. I.; Bradley, S. A.; Wen, J.; Mishra, B.; Kelly, S. D.; Bare, S. R. Aberration-Corrected Transmission Electron Microscopy and In Situ XAFS Structural Characterization of $\mathrm{Pt} / \gamma-\mathrm{Al}_{2} \mathrm{O}_{3}$ Nanoparticles. ChemCatChem 2015, 7, 3779-3787.

(14) Jahel, A.; Avenier, P.; Lacombe, S.; Olivier-Fourcade, J.; Jumas, J.-C. Effect of indium in trimetallic $\mathrm{Pt} / \mathrm{Al}_{2} \mathrm{O}_{3} \mathrm{SnIn}-\mathrm{Cl}$ naphthareforming catalysts. J. Catal. 2010, 272, 275-286.

(15) Jahel, A.; Moizan-Baslé, V.; Chizallet, C.; Raybaud, P.; Olivier-Fourcade, J.; Jumas, J.-C.; Avenier, P.; Lacombe, S. Effect of Indium Doping of $\gamma$-Alumina on the Stabilization of PtSn Alloyed Clusters Prepared by Surface Organostannic Chemistry. J. Phys. Chem. C 2012, 116, 10073-10083.

(16) Lee, J.; Jang, E. J.; Kwak, J. H. Effect of number and properties of specific sites on alumina surfaces for $\mathrm{Pt}-\mathrm{Al}_{2} \mathrm{O}_{3}$ catalysts. Appl. Catal., A 2019, 569, 8-19.

(17) Singh, J.; Nelson, R. C.; Vicente, B. C.; Scott, S. L.; van Bokhoven, J. A. Electronic structure of alumina-supported monometallic Pt and bimetallic PtSn catalysts under hydrogen and carbon monoxide environment. Phys. Chem. Chem. Phys. 2010, 12, 56685677.

(18) Dessal, C.; Sangnier, A.; Chizallet, C.; Dujardin, C.; Morfin, F.; Rousset, J.-L.; Aouine, M.; Bugnet, M.; Afanasiev, P.; Piccolo, L. Atmosphere-dependent stability and mobility of catalytic Pt single atoms and clusters on $\gamma-\mathrm{Al}_{2} \mathrm{O}_{3}$. Nanoscale 2019, 11, 6897-6904.

(19) Vaarkamp, M.; Miller, J. T.; Modica, F. S.; Koningsberger, D. C. On the Relation between Particle Morphology, Structure of the Metal-Support Interface, and Catalytic Properties of $\mathrm{Pt} / \gamma-\mathrm{Al}_{2} \mathrm{O}_{3}$. J. Catal. 1996, 163, 294-305.
(20) Ahmadi, M.; Mistry, H.; Roldan Cuenya, B. Tailoring the Catalytic Properties of Metal Nanoparticles via Support Interactions. J. Phys. Chem. Lett. 2016, 7, 3519-3533.

(21) Hu, C. H.; Chizallet, C.; Mager-Maury, C.; Corral-Valero, M.; Sautet, P.; Toulhoat, H.; Raybaud, P. Modulation of catalyst particle structure upon support hydroxylation: $\mathrm{Ab}$ initio insights into $\mathrm{Pd}_{13}$ and $\mathrm{Pt}_{13} / \gamma-\mathrm{Al}_{2} \mathrm{O}_{3}$. J. Catal. 2010, 274, 99-110.

(22) Gorczyca, A.; Raybaud, P.; Moizan, V.; Joly, Y.; Chizallet, C. Atomistic Models for Highly-dispersed $\mathrm{PtSn} / \gamma-\mathrm{Al}_{2} \mathrm{O}_{3}$ Catalysts: Ductility and Dilution Affect the Affinity for Hydrogen. ChemCatChem 2019, 500, 271.

(23) Mager-Maury, C.; Bonnard, G.; Chizallet, C.; Sautet, P.; Raybaud, P. $\mathrm{H}_{2}$-Induced Reconstruction of Supported Pt Clusters: MetalSupport Interaction versus Surface Hydride. ChemCatChem 2011, 3 , 200-207.

(24) Zhai, H.; Alexandrova, A. N. Local Fluxionality of SurfaceDeposited Cluster Catalysts: The Case of $\mathrm{Pt}_{7}$ on $\mathrm{Al}_{2} \mathrm{O}_{3}$. J. Phys. Chem. Lett. 2018, 9, 1696-1702.

(25) Sun, G.; Sautet, P. Metastable Structures in Cluster Catalysis from First-Principles: Structural Ensemble in Reaction Conditions and Metastability Triggered Reactivity. J. Am. Chem. Soc. 2018, 140, 2812-2820.

(26) Vila, F. D.; Rehr, J. J.; Nuzzo, R. G.; Frenkel, A. I. Anomalous Structural Disorder in Supported Pt Nanoparticles. J. Phys. Chem. Lett. 2017, 8, 3284-3288.

(27) Zhai, H.; Alexandrova, A. N. Fluxionality of Catalytic Clusters: When It Matters and How to Address It. ACS Catal 2017, 7 1905-1911.

(28) Sangnier, A.; Matrat, M.; Nicolle, A.; Dujardin, C.; Chizallet, C. Multiscale Approach to the Dissociative Adsorption of Oxygen on a Highly Dispersed Platinum Supported on $\gamma-\mathrm{Al}_{2} \mathrm{O}_{3}$. J. Phys. Chem. C 2018, 122, 26974-26986.

(29) Sinfelt, J. H. Bifunctional Catalysis. Adv. Chem. Eng. 1964, 5, $37-74$

(30) Acido-basic catalysis: Application to refining and petrochemistry; Vol. 2, 10. Catalytic Reforming, p. 583. Marcilly, C., Ed.; Editions Technip: Paris, 2006.

(31) Zečević, J.; Vanbutsele, G.; Jong, K. P. de; Martens, J. A. Nanoscale intimacy in bifunctional catalysts for selective conversion of hydrocarbons. Nature 2015, 528, 245-248.

(32) P. B. Weisz. Polyfunctional Heterogeneous Catalysis. Adv. Catal. 1962, 13, 137-190.

(33) L. Kovarik; A. Genç; C. Wang; J. Szanyi; C. Peden; J. Kwak. Tomography and high resolution study of gamma- $\mathrm{Al}_{2} \mathrm{O}_{3}$ porosity, surfaces and Pt surface interaction. Microsc. Microanal. 2012, 18 , 1302-1303.

(34) le Goff, P.-Y.; Kostka, W.; Ross, J. Catalytic reforming. Springer Handbook of Petroleum Technology, $2^{\text {nd }}$ edition; Springer handbooks; Springer: New York, 2017; pp 589-616.

(35) Dessal, C.; Len, T.; Morfin, F.; Rousset, J.-L.; Aouine, M.; Afanasiev, P.; Piccolo, L. Dynamics of Single Pt Atoms on Alumina during CO Oxidation Monitored by Operando X-ray and Infrared Spectroscopies. ACS Catal 2019, 9, 5752-5759.

(36) Yang, E.; Jang, E. J.; Lee, J. G.; Yoon, S.; Lee, J.; Musselwhite, N.; Somorjai, G. A.; Kwak, J. H.; An, K. Acidic effect of porous alumina as supports for Pt nanoparticle catalysts in nhexane reforming. Catal. Sci. Technol. 2018, 8, 3295-3303.

(37) Mei, D.; Kwak, J. H.; Hu, J.; Cho, S. J.; Szanyi, J.; Allard, L. F.; Peden, C. H. F. Unique Role of Anchoring Penta-Coordinated Al

${ }^{+}$Sites in the Sintering of $\gamma-\mathrm{Al}_{2} \mathrm{O}_{3}$-Supported Pt Catalysts. J. Phys. Chem. Lett. 2010, 1, 2688-2691.

(38) Zhang, Z.; Chen, Y.; Zhou, L.; Chen, C.; Han, Z.; Zhang, B.; Wu, Q.; Yang, L.; Du, L.; Bu, Y.; Wang, P.; Wang, X.; Yang, H.; Hu, Z. The simplest construction of single-site catalysts by the synergism of micropore trapping and nitrogen anchoring. Nat. Commun., 10, 1657.

(39) Bruix, A.; Lykhach, Y.; Matolínová, I.; Neitzel, A.; Skála, T.; Tsud, N.; Vorokhta, M.; Stetsovych, V.; Ševčíková, K.; Mysliveček, 
J.; Fiala, R.; Václavů, M.; Prince, K. C.; Bruyère, S.; Potin, V.; Illas, F.; Matolín, V.; Libuda, J.; Neyman, K. M. Maximum noble-metal efficiency in catalytic materials: atomically dispersed surface platinum. Angew. Chem. Int. Ed. 2014, 53, 10525-10530.

(40) Jones, J.; Xiong, H.; DeLaRiva, A. T.; Peterson, E. J.; Pham, H.; Challa, S. R.; Qi, G.; Oh, S.; Wiebenga, M. H.; Hernández, X. I. P.; Wang, Y.; Datye, A. K. Thermally stable single-atom platinumon-ceria catalysts via atom trapping. Science 2016, 353, 150-154.

(41) Kunwar, D.; Zhou, S.; DeLaRiva, A.; Peterson, E. J.; Xiong, H.; Pereira-Hernández, X. I.; Purdy, S. C.; ter Veen, R.; Brongersma, H. H.; Miller, J. T.; Hashiguchi, H.; Kovarik, L.; Lin, S.; Guo, H.; Wang, Y.; Datye, A. K. Stabilizing High Metal Loadings of Thermally Stable Platinum Single Atoms on an Industrial Catalyst Support. ACS Catal 2019, 9, 3978-3990.

(42) Pereira-Hernández, X. I.; DeLaRiva, A.; Muravev, V.; Kunwar, D.; Xiong, H.; Sudduth, B.; Engelhard, M.; Kovarik, L.; Hensen, E. J. M.; Wang, Y.; Datye, A. K. Tuning Pt- $\mathrm{CeO}_{2}$ interactions by high-temperature vapor-phase synthesis for improved reducibility of lattice oxygen. Nat. Commun. 2019, 10, 1358.

(43) González, J. C.; Hernández, J. C.; López-Haro, M.; del Río, E.; Delgado, J. J.; Hungría, A. B.; Trasobares, S.; Bernal, S.; Midgley, P. A.; Calvino, J. J. 3 D characterization of gold nanoparticles supported on heavy metal oxide catalysts by HAADF-STEM electron tomography. Angew. Chem. Int. Ed. 2009, 48, 5313-5315.

(44) Midgley, P. A.; Weyland, M.; Thomas, J. M.; Johnson, B. F. G. Z-Contrast tomography: a technique in three-dimensional nanostructural analysis based on Rutherford scattering. Chem. Commun. 2001, 907-908.

(45) Hernández-Garrido, J.; Yoshida, K.; Gai, P.; Boyes, E.; Christensen, C. H.; Midgley, P. A. The location of gold nanoparticles on titania: A study by high resolution aberration-corrected electron microscopy and 3D electron tomography. Catal. Today 2011, 160, $165-169$.

(46) Friedrich, H.; Jongh, P. E. de; Verkleij, A. J.; Jong, K. P. de. Electron Tomography for Heterogeneous Catalysts and Related Nanostructured Materials. Chem. Rev. 2009, 109, 1613-1629.

(47) Li, Y.; Zakharov, D.; Zhao, S.; Tappero, R.; Jung, U.; Elsen, A.; Baumann, P.; Nuzzo, R. G.; Stach, E. A.; Frenkel, A. I. Complex structural dynamics of nanocatalysts revealed in Operando conditions by correlated imaging and spectroscopy probes. Nat. Commun. 2015, 6, 7583-7589.

(48) Vendelbo, S. B.; Elkjær, C. F.; Falsig, H.; Puspitasari, I.; Dona, P.; Mele, L.; Morana, B.; Nelissen, B. J.; van Rijn, R.; Creemer, J. F.; Kooyman, P. J.; Helveg, S. Visualization of oscillatory behaviour of Pt nanoparticles catalysing CO oxidation. Nat. Mater. 2014, 13, 884-890.

(49) Dembele, K.; Moldovan, S.; Hirlimann, C.; Harmel, J.; Soulantica, K.; Serp, P.; Chaudret, B.; Gay, A.-S.; Maury, S.; Berliet, A.; Fecant, A.; Ersen, O. Reactivity and structural evolution of urchinlike Co nanostructures under controlled environments. J. Microsc. 2018, 269, 168-176.

(50) Allard, L. F.; Overbury, S. H.; Bigelow, W. C.; Katz, M. B.; Nackashi, D. P.; Damiano, J. Novel MEMS-based gas-cell/heating specimen holder provides advanced imaging capabilities for in situ reaction studies. Microsc. Microanal. 2012, 18, 656-666.

(51) J. Berdala; E. Freund; J.P. Lynch. Environment of Platinum atoms in a $\mathrm{H}_{2} \mathrm{PtCl}_{6} / \mathrm{Al}_{2} \mathrm{O}_{3}$ catalysts: influence of metal loading and chlorine content. J. Phys. 1986, 47.

(52) Lynch, J. Development of Structural Characterisation Tools for Catalysts. Oil Gas Sci. Technol. 2002, 57, 281-305.

(53) Mager-Maury, C.; Chizallet, C.; Sautet, P.; Raybaud, P. Platinum Nanoclusters Stabilized on $\gamma$-Alumina by Chlorine Used As a Capping Surface Ligand: A Density Functional Theory Study. ACS Catal. 2012, 2, 1346-1357.

(54) Mastronarde, D. N. Dual-Axis Tomography: An Approach with Alignment Methods That Preserve Resolution. J. Struct. Biol. 1997, 120, 343-352.
(55) Gordon, R.; Bender, R.; Herman, G. T. Algebraic Reconstruction Techniques (ART) for three-dimensional electron microscopy and X-ray photography. J. Theor. Biol. 1970, 29, 471-481.

(56) Messaoudii, C.; Boudier, T.; Sanchez Sorzano, C. O.; Marco, $\mathrm{S}$. TomoJ: Tomography software for three-dimensional reconstruction in transmission electron microscopy. BMC Bioinf. 2007, 8, 288-292.

(57) Fedorov, A.; Beichel, R.; Kalpathy-Cramer, J.; Finet, J.; Fillion-Robin, J.-C.; Pujol, S.; Bauer, C.; Jennings, D.; Fennessy, F.; Sonka, M.; Buatti, J.; Aylward, S.; Miller, J. V.; Pieper, S.; Kikinis, R. 3D Slicer as an image computing platform for the Quantitative Imaging Network. Magn. Reson. Imaging 2012, 30, 1323-1341.

(58) 3DSlicer. https://www.slicer.org/.

(59) Chaniot, J.; Moreaud, M.; Sorbier, L.; Fournel, T.; Becker, J.M. Tortuosimetric operator for complex porous media characterization. Image Anal Stereol 2019, 38, 25-41.

(60) plugim!: M-tortuosity. https://www.plugim.fr/plugin/57.

(61) Steinmann, S. N.; Corminboeuf, C. Comprehensive Benchmarking of a Density-Dependent Dispersion Correction. J. Chem. Theory Comput. 2011, 7, 3567-3577.

(62) Perdew, J. P.; Burke, K.; Ernzerhof, M. Generalized Gradient Approximation Made Simple. Phys. Rev. Lett. 1996, 77, 3865-3868.

(63) Kresse, G.; Joubert, D. From ultrasoft pseudopotentials to the projector augmented-wave method. Phys. Rev. B 1999, 59, 17581775 .

(64) Kresse, G.; Hafner, J. Ab initio molecular-dynamics simulation of the liquid-metal-amorphous-semiconductor transition in germanium. Phys. Rev. B 1994, 49, 14251-14269.

(65) Kresse, G.; Furthmüller, J. Efficiency of ab-initio total energy calculations for metals and semiconductors using a plane-wave basis set. Comp. Mater. Sci. 1996, 6, 15-50.

(66) Batista, A. T. F.; Wisser, D.; Pigeon, T.; Gajan, D.; Diehl, F.; Rivallan, M.; Catita, L.; Gay, A.-S.; Lesage, A.; Chizallet, C.; Raybaud, $\mathrm{P}$. Beyond gamma- $\mathrm{Al}_{2} \mathrm{O}_{3}$ crystallite surfaces: the hidden features of Edges revealed by Solid-State ${ }^{1} \mathrm{H}$ NMR and DFT calculations. J. Catal. 2019, 378, 140-143.

(67) Krokidis, X.; Raybaud, P.; Gobichon, A.-E.; Rebours, B.; Euzen, P.; Toulhoat, H. Theoretical Study of the Dehydration Process of Boehmite to $\gamma$-Alumina. J. Phys. Chem. B 2001, 105, 5121-5130.

(68) Proux, O.; Lahera, E.; Del Net, W.; Kieffer, I.; Rovezzi, M.; Testemale, D.; Irar, M.; Thomas, S.; Aguilar-Tapia, A.; Bazarkina, E. F.; Prat, A.; Tella, M.; Auffan, M.; Rose, J.; Hazemann, J.-L. HighEnergy Resolution Fluorescence Detected X-Ray Absorption Spectroscopy: A Powerful New Structural Tool in Environmental Biogeochemistry Sciences. J. Environ. Qual. 2017, 46, 1146-1157.

(69) Aguilar-Tapia, A.; Ould-Chikh, S.; Lahera, E.; Prat, A.; Delnet, W.; Proux, O.; Kieffer, I.; Basset, J.-M.; Takanabe, K.; Hazemann, J.-L. A new high temperature reactor for operando XAS: Application for the dry reforming of methane over $\mathrm{Ni} / \mathrm{ZrO}_{2}$ catalyst. Rev. Sci. Instrum. 2018, 89, 35109.

(70) Ravel, B.; Newville, M. Athena, Artemis, Hephaestus: Data analysis for X-ray absorption spectroscopy using IFEFFIT. J. Synchrotron Radiat. 2005, 12, 537-541.

(71) Lietz, G.; Lieske, H.; Spindler, H.; Hanke, W.; Völter, J. Reactions of platinum in oxygen- and hydrogen-treated Pt $\gamma-\mathrm{Al} 2 \mathrm{O} 3$ catalysts: II. Ultraviolet-visible studies, sintering of platinum, and soluble platinum. J. Catal. 1983, 81, 17-25.

(72) Busca, G. The surface of transitional aluminas: A critical review. Catal. Today 2014, 226, 2-13.

(73) Prieto, G.; Zečević, J.; Friedrich, H.; de Jong, K. P.; de Jongh, P. E. Towards stable catalysts by controlling collective properties of supported metal nanoparticles. Nat. Mater. 2013, 12, 34-39. 
For Table of Contents Only

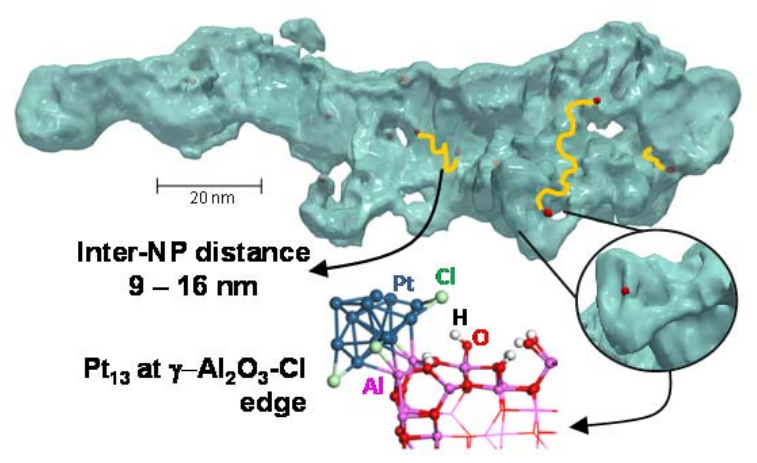

